\title{
Yellow dye laser thermotherapy of choroidal neovascularisation in age related macular degeneration
}

\author{
Margo R Beintema, Jendo A Oosterhuis, Fred Hendrikse
}

\begin{abstract}
Aim-A pilot study of the feasibility of using dye laser thermotherapy (LTT) at a subcoagulation temperature to occlude newly formed vessels in patients with age related macular degeneration (AMD).

Methods-Choroidal neovascularisation (CNV) in 24 eyes with exudative AMD was treated with a continuous wave yellow laser at $578 \mathrm{~nm}$. Parameters were an exposure time of 2 or 5 seconds, a spot size of 750 or $1000 \mu \mathrm{m}$, and a laser power of 100-200 $\mathrm{mW}$. The clinical end point was a greyish discoloration at the treatment site. The effect of thermotherapy was documented by ophthalmoscopic and fluorescein angiographic examination. The follow up after LTT was 4-16 months, mean 5 months.

Results-LTT resulted in total occlusion of newly formed vessels in 15 eyes $(62.5 \%)$. Neovascular outgrowth within 6 weeks and recurrences 2-4 months after LTT were observed, each in three eyes. In six of the nine eyes with occlusion of CNV without recurrence the choriocapillaris remained perfused; in two eyes only the large choroidal vessels remained perfused. In six eyes pigmentary changes were the only ophthalmoscopic and fluorescein angiographic signs of treatment. The effect of LTT is rather unpredictable.

Conclusion-CNV in AMD can effectively be treated by yellow dye laser thermotherapy with preservation of choroidal perfusion. The technique requires dosimetric adaptation.

(Br f Ophthalmol 2001;85:708-713)
\end{abstract}

University Eye Department, Maastricht, Netherlands M R Beintema

F Hendrikse

Leiden University Medical Centre, Netherlands

$\mathrm{J}$ A Oosterhuis

Correspondence to: M R Beintema, Department of Ophthalmology, Academic Hospital Maastricht, PO Box 5800, 6202 AZ Maastricht, Netherlands

mbei@ soog.azm.nl

Accepted for publication 24 January 2001
Laser photocoagulation is a common treatment for choroidal neovascularisation (CNV) secondary to age related macular degeneration (AMD). Newly formed vessels become occluded at coagulation temperatures of $65^{\circ} \mathrm{C}$ and higher. Both retina and choroid in the treated area become necrotic and develop into an atrophic or fibrotic scar. ${ }^{1}$ Blood vessels can also be occluded by transpupillary laser thermotherapy (LTT) at lower, subcoagulation temperatures of $45-60^{\circ} \mathrm{C}$, as is evident from studies of transpupillary LTT of choroidal melanomas. $^{2-4}$ Temperatures in this range cause necrosis of both tumour cells and endothelial cells mediated by nuclear pyknosis and mitochondrial damage, which block cell metabolism. ${ }^{3}$

This pilot study investigated whether yellow dye laser thermotherapy can be used to cause selective occlusion of newly formed vessels in AMD with sparing of the sensory retina and maintenance of choroidal perfusion.

\section{Material and methods}

LTT was performed in 24 eyes of 24 patients with AMD and fluorescein angiographic evidence of CNV in the macula. All eyes had the classic type of CNV; in three eyes it was combined with an occult component with late leakage of an undetermined not well demarcated source in the early phase. All patients had a general ophthalmological examination before treatment, which included measurement of best corrected Snellen visual acuity, slit lamp and fluorescein angiographic examination. Ophthalmological data are summarised in Table 1. Visual complaints existed for 1-20 weeks; in 14 patients they existed for 6 weeks or longer. Twenty eyes had a visual acuity of $1 / 60$ to 0.16 and four eyes an acuity of 0.2 to 0.4. In 13 eyes the CNV also affected the subfoveal area. Eyes were included that had the classic type of CNV or with both the occult and the classic type of CNV, when the area of the occult CNV did not exceed half of the total CNV affected area. Fifteen eyes showed subretinal haemorrhages, partly obscuring the neovascular network. In 12 eyes incipient fibrosis had developed in the exudative lesion.

Yellow dye laser radiation was used for laser thermotherapy because at its wavelength of 578 $\mathrm{nm}$ absorption by oxyhaemoglobin is maximal. ${ }^{5}$ Treatment parameters were comparable to those of transpupillary LTT of choroidal melanomas - namely, a long exposure time ( 2 or 5 seconds), a low power setting (100-200 mW), and a large diameter of the laser beam (750 or $1000 \mu \mathrm{m}) .{ }^{26}$ Treatment was performed over the entire lesion with a pattern of multiple confluent applications, mean number 11 (range 4-20), with the exclusion of the area of subfoveally located newly formed vessels. A rather low energy level of the laser was used initially, which did not cause an ophthalmoscopically visible effect. The energy level was then increased stepwise until a slightly greyish discoloration of the CNV complex developed at the end of the exposure time. A white coagulation effect was intentionally avoided. The difference between a photocoagulation spot in the macula and a thermotherapeutic lesion just after delivery is shown in Figure 1. The follow up after LTT was 4-16 months, with a mean of 5 months.

Treatment results were evaluated by ophthalmoscopic, photographic, and fluorescein angiographic examination at 4, 6, 9, and 16 weeks after LTT, and thereafter every 3 months. 
Table 1 Yellow dye laserthermotherapy (LTT) of CNV in AMD. Clinical data and results of LTT in 24 patients

\begin{tabular}{|c|c|c|c|c|c|c|c|c|c|}
\hline Patient & $\begin{array}{l}\text { Visual symptoms } \\
\text { (weeks) }\end{array}$ & $\begin{array}{l}\text { Area of } \\
C N V(D A)\end{array}$ & $\begin{array}{l}C N V \\
\text { details }\end{array}$ & $\begin{array}{l}\text { Haem } \\
\text { fibrosis }\end{array}$ & $\begin{array}{l}\text { Result LTT } \\
\geqslant 6 \text { weeks }\end{array}$ & $\begin{array}{l}\text { Choroidal } \\
\text { perfusion }\end{array}$ & $\begin{array}{l}\text { Result LTT } \\
4 \text { months }\end{array}$ & $\begin{array}{l}\text { Visual acuity } \\
\text { pre-LTT }\end{array}$ & $\begin{array}{l}\text { Visual acuity } \\
\text { post-LTT }\end{array}$ \\
\hline 1 & 5 & 3 & $\mathrm{~S} / \mathrm{C}$ & - & + & + & ++++ & $1 / 60$ & $=$ \\
\hline 2 & 6 & 1 & $\mathrm{~S} / \mathrm{C}$ & $\mathrm{H}$ & - & - & $\mathrm{O}$ & 0.1 & 0.08 \\
\hline 3 & 5 & 1 & $\mathrm{C}$ & - & + & - & ++++ & 0.2 & $=$ \\
\hline 4 & 4 & 2 & C & - & + & + & ++++ & 0.25 & $=$ \\
\hline 5 & 1 & 1 & $\mathrm{C}$ & $\mathrm{H}$ & - & - & $\mathrm{O}$ & 0.08 & $1 / 60$ \\
\hline 6 & 10 & 2 & C & $\mathrm{F}$ & + & - & ++++ & $1 / 60$ & $=$ \\
\hline 7 & 5 & 3 & C & - & - & - & no effect & $1 / 60$ & $=$ \\
\hline 8 & 5 & 3 & $\mathrm{~S} / \mathrm{O}$ & $\mathrm{H} / \mathrm{F}$ & + & + & ++++ & 0.16 & $=$ \\
\hline 9 & 2 & 3 & $\mathrm{~S} / \mathrm{C}$ & $\mathrm{H} / \mathrm{F}$ & - & - & no effect & 0.12 & $=$ \\
\hline 10 & 10 & 3 & $\mathrm{~S} / \mathrm{C}$ & $\mathrm{H} / \mathrm{F}$ & - & - & no effect & 0.12 & $=$ \\
\hline 11 & 10 & 1 & $\mathrm{~S} / \mathrm{C}$ & - & + & + & $\mathrm{R}$ & $1 / 60$ & $=$ \\
\hline 12 & 8 & 2 & $\mathrm{C}$ & $\mathrm{H}$ & + & - & ++++ & 0.16 & $=$ \\
\hline 13 & 4 & 1 & $\mathrm{~S} / \mathrm{C}$ & $\mathrm{H}$ & + & + & ++++ & 0.08 & $=$ \\
\hline 14 & 20 & 4 & $\mathrm{~S} / \mathrm{C}$ & $\mathrm{H} / \mathrm{F}$ & - & - & $\mathrm{O}$ & 0.08 & $=$ \\
\hline 15 & 16 & 5 & $\mathrm{~S} / \mathrm{C}$ & $\mathrm{F}$ & + & - & ++++ & $1 / 60$ & $=$ \\
\hline 16 & 3 & 1 & $\mathrm{C}$ & $\mathrm{H}$ & + & + & ++++ & 0.1 & $=$ \\
\hline 17 & 12 & 2 & $\mathrm{~S} / \mathrm{C}$ & $\mathrm{H} / \mathrm{F}$ & - & + & $\mathrm{P}$ & $1 / 60$ & $=$ \\
\hline 18 & 16 & 1 & $\mathrm{O}$ & $\mathrm{H} / \mathrm{F}$ & + & + & $\mathrm{R}$ & 0.08 & 0.2 \\
\hline 19 & 6 & 2 & $\mathrm{O}$ & $\mathrm{H} / \mathrm{F}$ & - & - & $\mathrm{P}$ & 0.08 & $1 / 60$ \\
\hline 20 & 16 & 4 & $\mathrm{~S} / \mathrm{C}$ & $\mathrm{H} / \mathrm{F}$ & - & - & no effect & $1 / 60$ & $=$ \\
\hline 21 & 18 & 4 & $\mathrm{~S} / \mathrm{C}$ & $\mathrm{H} / \mathrm{F}$ & - & - & no effect & $1 / 60$ & $=$ \\
\hline 22 & 20 & 2 & $\mathrm{~S} / \mathrm{C}$ & $\mathrm{H} / \mathrm{F}$ & + & + & $\mathrm{R}$ & $1 / 60$ & $1 / 300$ \\
\hline 23 & 8 & 1 & $\mathrm{C}$ & - & - & - & $\mathrm{P}$ & 0.4 & 0.1 \\
\hline 24 & 5 & 1 & C & $\mathrm{H}$ & - & - & $\mathrm{P}$ & 0.3 & 0.2 \\
\hline
\end{tabular}

Patients in alphabetic sequence. $\mathrm{DA}=$ disc area; $C N V$ details: $\mathrm{S}=\mathrm{CNV}$ also subfoveally located; $\mathrm{C}=$ classic $\mathrm{CNV} ; \mathrm{O}=\mathrm{CNV}$ partly occult; $\mathrm{H}=$ haemorrhage partly obscuring the CNV; F= subretinal fibrosis Results LTT $\geqslant 6$ weeks (column 6 ) $+=$ total disappearance of CNV on fluorescein angiogram. Choroidal perfusion (column 7 ) $+=$ presence of choriocapillaris perfusion. Results LTT 4 months (column 8 ) $++++=$ no recurrence of CNV R $=$ recurrence after 2 months of total regression CNV. $\mathrm{O}=$ outgrowth $\mathrm{CNV}$ within 6 weeks. $\mathrm{P}=$ partial regression of CNV. Visual acuity post treatment (column 10 ): $=$ means unchanged visual acuity.

The outcome was classified as favourable when the CNV had totally regressed on fluorescein angiographic examination and remained so for minimally 6 weeks. Results were classified as unfavourable when there was incomplete destruction of the CNV or when neovascular outgrowth developed within 6 weeks after initially complete angiographic regression of the $\mathrm{CNV}$.

\section{Results}

Treatment results are summarised in Tables 1 and 2 . In 15 of 24 eyes $(62.5 \%)$ LTT resulted in complete occlusion of the $\mathrm{CNV}$ on fluorescein angiography 4 weeks after LTT as evidenced by lack of hyperfluorescence and leakage from the neovascular network, also in the late phase. In three of the 15 successfully treated eyes (20\%) neovascular outgrowth developed 4-6 weeks after LTT. In another three successfully treated eyes $(20 \%)$ CNV recurred 2-4 months after

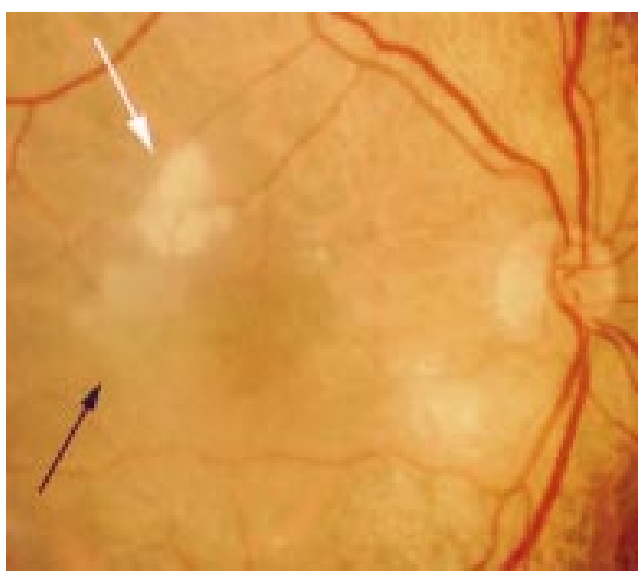

Figure 1 Patient with a neovascular membrane in AMD documented directly after treatment. The CNV is partly treated by photocoagulation and partly by LTT to show the difference in ophthalmoscopic appearance: the

photocoagulation treated area is white (white arrow), the thermotherapy treated area is greyish (black arrow).
Table 2 Results of LTT 4 months post-treatment

Results of laser thermotherapy in 24 eyes

\begin{tabular}{ll}
\hline Favourable in 12 eyes & $\begin{array}{l}\text { 12 eyes: complete occlusion of CNV, } \\
\text { CNV recurrence in three eyes 2-4 } \\
\text { months after LTT }\end{array}$ \\
Unfavourable in 12 eyes & $\begin{array}{l}\text { three eyes: complete occlusion of } \\
\text { CNV with neovascular outgrowth } \\
\text { within } 6 \text { weeks after LTT. } \\
\text { four eyes: partial regression of CNV. } \\
\text { five eyes: no effect of LTT on CNV }\end{array}$
\end{tabular}

LTT (Fig 5). Thus, in nine of the 15 initially successfully treated eyes $(60 \%)$ the neovascular network regressed without recurrence. In six of these nine eyes the LTT induced effect was remarkably mild, because apart from regression of the exudative lesion, slight chorioretinal atrophy, and some hyperpigmentation in the treated area were the only ophthalmoscopic findings (Figs 2, 3). Regression of the CNV was not associated with the development of subretinal fibrosis. In four successfully treated eyes, chorioretinal fibrosis was already present before LTT but did not progress after treatment. Atrophic scar formation occurred in the treatment area in three eyes and resulted in chorioretinal atrophy 4-8 months after LTT. This did not cause loss of visual acuity because in these cases LTT was not performed in the foveal area (Fig 4).

Perfusion of the large choroidal vessels and choriocapillaris was seen on fluorescein angiograms in nine of the 12 favourably ( $>6$ weeks) responding eyes (Fig $3 \mathrm{C}$ ). In the other three eyes the choriocapillaris became occluded but non-leaking large choroidal vessels remained perfused. The perifoveal retinal capillary network remained perfused after treatment (Fig 3B, 5B).

LTT treatment failed in 12 eyes: in four destruction of the CNV was incomplete, in five LTT had no visible effect on the CNV, and in three there was early neovascular outgrowth. Retreatment with LTT was not done in this 

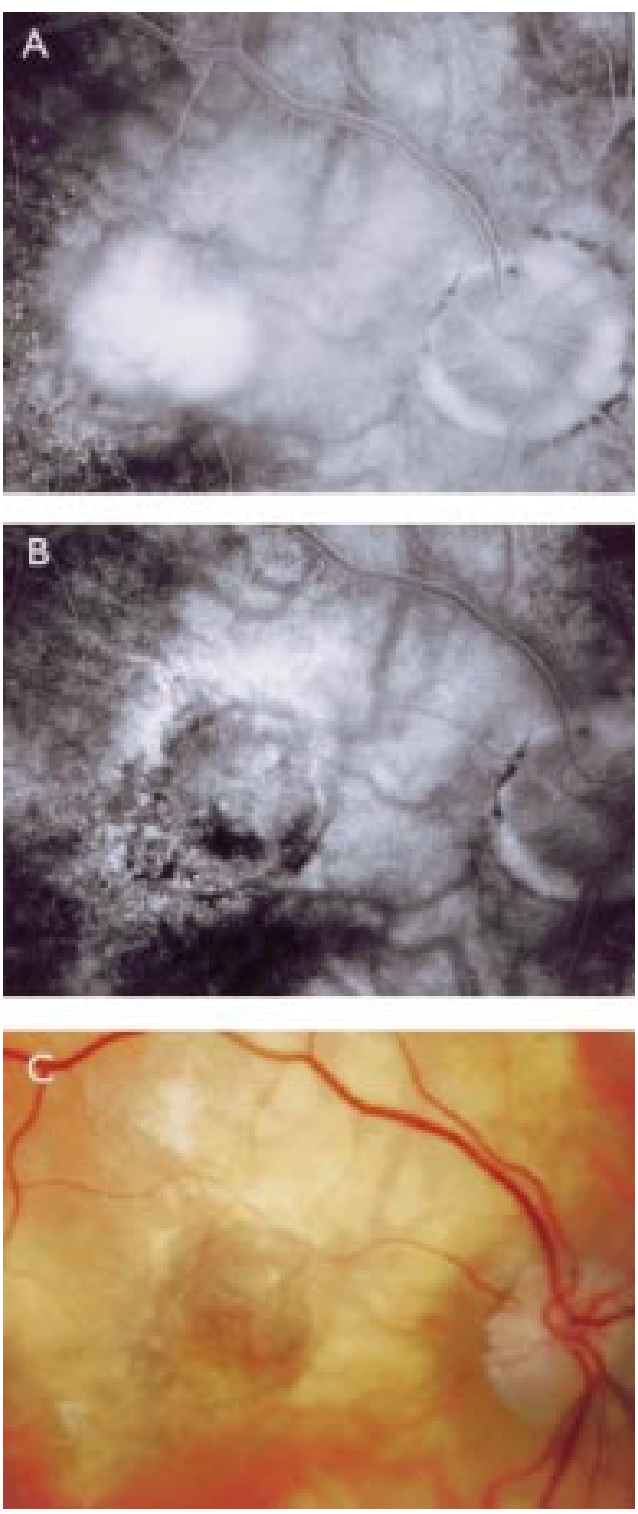

Figure 2 (A) Late phase angiography of patient 16 with a subfoveal neovascular membrane before LTT. (B) Late phase fluorescein angiogram 6 weeks after LTT shows total regression of the CNV with perfusion of the choroidal circulation. (C) Four months after LTT the fundus shows only a slight diffuse pigmentation in the treated area without signs of choroidal occlusion or fibrotic scar formation. Visual acuity remained unchanged 0.1.

pilot study. Haemorrhages or other treatment related complications were not observed during or after LTT.

The majority of patients $(66 \%)$ had considerable loss of central vision (visual acuity 0.1 or less) before treatment. After LTT visual acuity remained unchanged in 17 eyes, it decreased in six, and increased in one eye. In the nine successfully treated eyes the visual acuity remained unchanged (Table 1).

\section{Discussion}

In this pilot study we investigated the potential of LTT as a new treatment for CNV in exudative AMD. Heat at a subcoagulation temperature in LTT occluded the CNV in 15 eyes $(62.5 \%)$. Four months after treatment CNV remained eradicated in nine eyes $(37.5 \%)$, as evidenced by fluorescein angiography. Neovascular outgrowth within 6 weeks after LTT was observed in three eyes. We classified these results as failures because the outgrowth in this short post-treatment period possibly originated from the CNV, which was not completely occluded by LTT but failed to show perfusion on the first fluorescein angiogram after LTT. Recurrences were observed in three eyes, 2-4 months after LTT.

The ophthalmoscopic results 4 months after LTT were variable, ranging from no visible effect in six eyes to the development of a mild atrophic chorioretinal scar in the treated area in three eyes. This variability was not related to the power setting of the laser or to the exposure time. It was unexpected because in all patients the end point of LTT was the development of a slight greyish discoloration of the fundus in the target area, which was the parameter for treatment intensity. This discoloration has proved to be a useful yardstick for the energy level to be used in transpupillary thermotherapy of choroidal melanomas. ${ }^{36}$ The difference in the effect of thermotherapy may be related to a large variation in the heat sensitivity of the retina. In rabbits clinically barely detectable diode laser lesions of the retina were associated with a variable tissue response in the microscopic specimens. ${ }^{7}$ The same results were obtained for eyes treated for 2 or 5 seconds. In addition, LTT treatment outcome did not depend on the duration of visual complaints, or on the size or localisation of the CNV and the presence of haemorrhages or fibrosis in the exudative lesion.

In all eyes which responded favourably to treatment the ophthalmoscopic and fluorescein angiographic damage to the retina and choroid was less after LTT than after photocoagulation treatment. In six eyes discrete pigmentary changes with slight chorioretinal atrophy in the treated area were the only funduscopic findings after LTT (Figs 2 and 3).

A perfusion defect in the choriocapillaris could account for the pathological changes in AMD because the choriocapillaris supplies the retinal pigment epithelium and outer retina. Ischaemia and hypoxia may trigger the development of new vessels, mediated by the vascular endothelial growth factor. ${ }^{8}$ There is considerable evidence of decreased choroidal perfusion in patients with AMD and a prolonged choriocapillaris filling time on angiography in patients with neovascular AMD..$^{9-16}$

For LTT we selected the power, spot size, exposure time, and wavelength so as to cause occlusion of newly formed vessels without interfering with the choroidal and retinal circulation. This is important because choroidal perfusion is essential for the function of the outer retinal layer and the retinal pigment epithelial layer. In 12 eyes with a favourable result after LTT it was possible to evaluate the choroidal circulation, which remained perfused in nine eyes $(75 \%)$; in two eyes the choriocapillaris became occluded but large choroidal vessels remained perfused, and in one eye it was difficult to evaluate. In all eyes 
the retinal vasculature was not damaged and perfusion was unchanged after LTT, indicating that heat was mainly produced at the CNV as target and was not conducted into the retina. The selective occlusion of the newly formed vessels can be explained by their increased vulnerability to heat compared with the normal vasculature. ${ }^{4}$ In addition, dissipation of heat by the choroid is very efficient because the fast circulation in its dense vascular network has a strong cooling effect. ${ }^{17}$ Even though choroidal perfusion persisted after LTT, recurrence of $\mathrm{CNV}$ was observed in three of 12 eyes after initially successful treatment. However, the
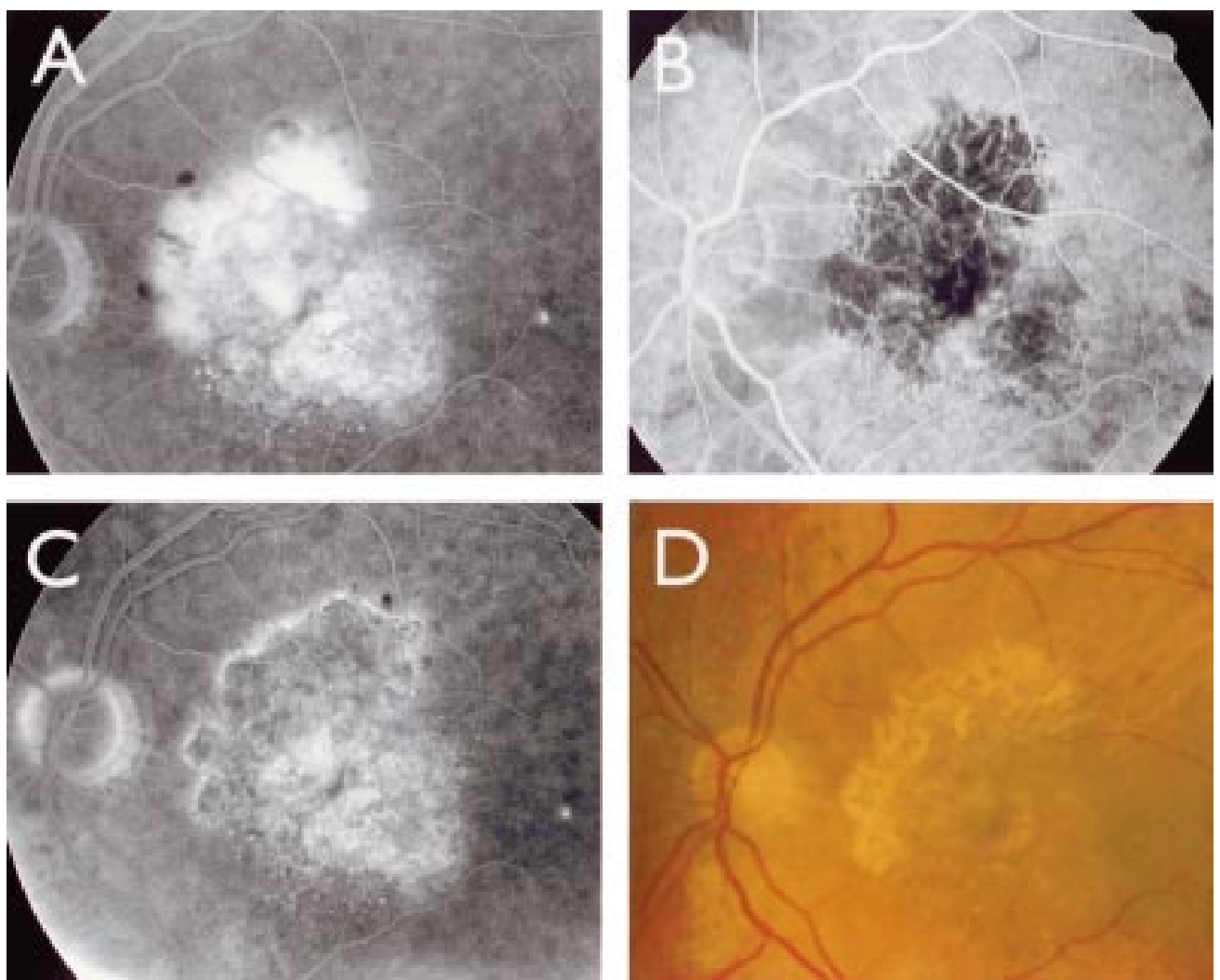

Figure 3 (A) Fluorescein angiogram of the fundus of patient 1, showing a partly subfoveally situated CNV extending superiorly and nasally. (B) The angiogram 9 weeks after LTT shows total occlusion of CNV, filling of the choroidal arteries in the treated area, and normal retinal vasculature. (C) Late phase angiography of the treated area shows diffuse fluorescence and hyperfluorescence in the foveal area 16 weeks after LTT. There are no signs of leakage. (D) Fundus appearance 6 months after LTT showing discrete pigmentary changes in the treated area, without fibrotic scar formation. In spite of the same power setting the outer zone of the treated area had a more atrophic appearance than the central treated area.
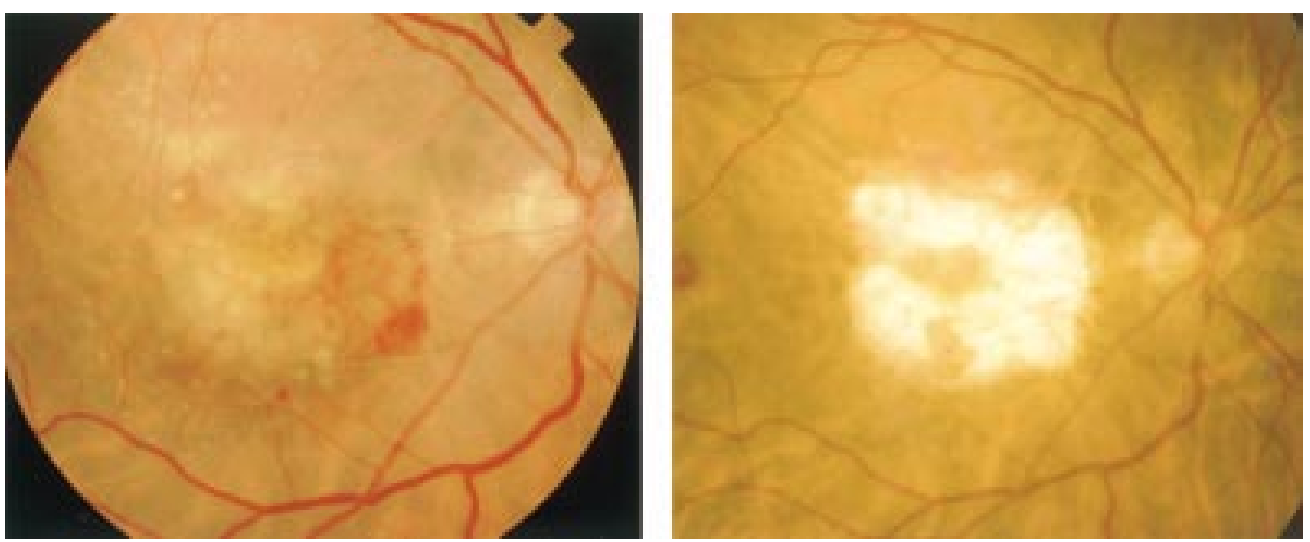

Figure 4 (A) Fundus of patient 8 with a haemorrhagic AMD, directly after LTT treatment of the CNV in the macular area. The effect of thermotherapy is seen as a just visible slightly greyish haze. (B) In 16 months after LTT the macula became atrophic, except the untreated foveal area; visual acuity remained unchanged at 0.16. 

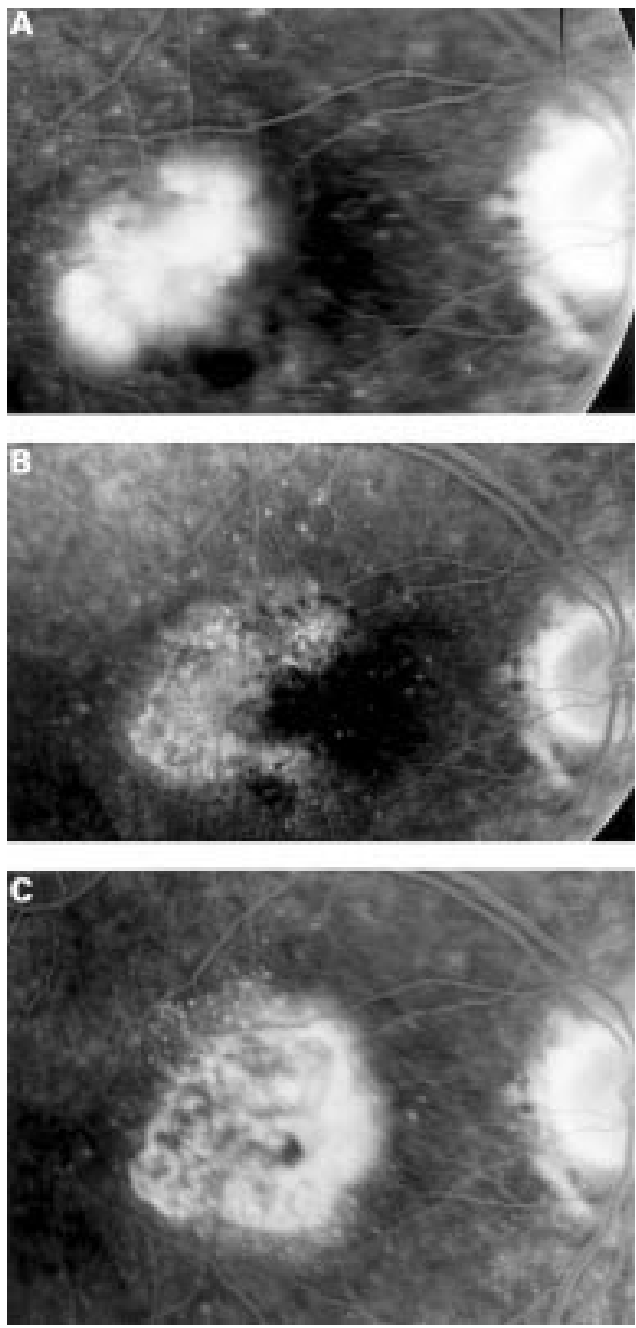

Figure 5 (A) Neovascular membrane, located in the foveomacular area in patient 22. Visual acuity 1/60. (B) Fluorescein angiography 10 weeks after LTT shows complete occlusion of the CNV; the hyperfluorescence of the treated area is indicative of perfusion of the choriocapillaris. There is no leakage. (C) Late phase angiogram 3 months after LTT shows recurrence of CNV at the nasal rim of the treated area.

fibrotic component of the $\mathrm{CNV}$, recurrence after photocoagulation, complaints for more than 2 months, and a visual acuity of less than $0.1 .^{19}{ }^{20}$ Nevertheless, fluorescein angiography showed occlusion of $\mathrm{CNV}$ in 15 of 24 eyes $(66.6 \%)$.

Visual acuity remained unchanged in $70 \%$ of the patients, but the low pretreatment visual acuity of 0.1 or less in 16 patients precluded a detailed evaluation of the results.

A recent article on transpupillary thermotherapy of occult subfoveal CNV in AMD, using a diode laser at $810 \mathrm{~nm}$, an exposure time of 60 seconds, and a power range between 360 $\mathrm{mW}$ and $1000 \mathrm{~mW}$, showed decreased exudation on fluorescein angiographs and optical coherence tomography in combination with improved clinical parameters in 15 of the 16 treated eyes. ${ }^{21}$ By selecting a yellow dye laser and shorter exposure times we aim at a more preferential uptake of radiation by oxyhaemoglobin in the newly formed vessels because depth of penetration, which is important in tumour therapy, was not required.
Other treatments, aiming at selective occlusion of CNV with minimal damage to the sensory retina and preservation of visual acuity have been introduced. The results of ionising radiation therapy of $\mathrm{CNV}$ in AMD are controversial. $^{22}{ }^{23}$ Photodynamic therapy with verteporfin as photosensitiser have shown promising results. In patients with classic CNV there was less than a 15 letter loss of visual acuity in $67 \%$ in the treated eyes versus $39 \%$ in the control group. As recurrences develop frequently, most patients require multiple treatments, on average 3.7 in the first year, with this expensive drug. ${ }^{24}$

The results of our pilot study show that CNV in AMD can effectively be occluded by transpupillary yellow dye LTT. With this technique light is converted into heat, preferentially at the CNV, thereby sparing the retinal and to some extent also the choroidal circulation. Unfortunately, the effect of LTT is rather unpredictable and the persistence of choroidal perfusion did not prevent the development of recurrences. When further developed, yellow dye LTT may become a useful option for treating $\mathrm{CNV}$ in $\mathrm{AMD}$.

1 Macular Photocoagulation Study Group. Krypton laser photocoagulation for neovascular lesions of age-related macular degeneration: results of a randomized clinical trial. Arch Ophthalmol 1990;108:816-24.

2 Journée-de Korver JG, Oosterhuis JA, Kakebeeke-Kemme $\mathrm{H}$, et al. Transpupillary thermotherapy (TTT) by infrared irradiation of choroidal melanoma. Doc Ophthalmol 1992; 82:185-91.

3 Journée-de Korver JG, Oosterhuis JA, Vrensen GFJM. Light and electron microscopic findings on experimental melanomas after hyperthermia at $50^{\circ} \mathrm{C}$. Melanoma Res 1995;5:393-405.

4 Reinhold HS, Endrich B Tumour microcirculation as a targer for hyperthermia. Int f Hyperthermia 1986;2:111-37.

5 Singerman LJ, Kalski RS, Tunable dye laser photocoagulation for choroidal neovascularization complicating agerelated macular degeneration. Retina 1989;9:247-57

6 Oosterhuis JA, Journée-de Korver JG, Kuenen JEE. Transpupillary thermotherapy. Results in 50 patients with choroidal melanoma. Arch Ophthalmol 1998;116:157-62.

7 Pollack J, Kim J, Pulodi J, et al. Tissue effect of subclinical diode laser treatment of the retina. Arch Ophthalmol 1998; 116:1633-9.

8 Amin R, Puklin JE, Frank RN. Growth factor localization in choroidal neovascular membranes of age-related macular degeneration. Invest Ophthalmol Vis Sci 1994;35:3178-88.

Duke-Elder S. System of ophthalmology. St Louis: CV Mosby, 1966;IX:609-13.

10 Pauleikoff D, Chen JC, Chisholm IH, et al. Choroidal perfusion abnormality with age-related Bruch's membrane change. Am f Ophthalmol 1990;109:211-17.

11 Chen JC, Fitzke FW, Pauleikoff D. Functinal loss in age-related Bruch's membrane change with choroidal perfusion defect. Invest Ophthalmol Vis Sci 1992;33:334-40.

12 Boker T, Fang T, Steinmetz R. Refraction error and choroidal perfusion characteristics in patients with choroidal neovascularisation and age-related macular degeneration. Ger f Ophthalmol 1993;2:10-13.

13 Remulla J, Gaudio A, Miller S, et al. Foveal electroretinograms and choroidal perfusion characteristics in fellow eyes of patients with unilateral neovascular age-related macular degeneration. Br f Ophthalmol 1995;79:558-61.

14 Friedman E, Krupsky S, Lane AML, et al. Ocular blood flow velocity in age-related macular degeneration. Ophthalmology 1995;102:640-6.

15 Grunwald JE, Hariprasad M, DuPont J. Foveolar choroidal blood flow in age-related macular degeneration. Invest Ophthalmol Vis Sci 1998;39:385-90.

16 Ross RD, Barofsky JM. Presumed macular choroidal watershed vascular filling, choroidal neovascularisation and systemic vascular disease in patients with age-related macular degeneration. Am f Ophthalmol 1998;125:71-80.

17 Svaasand LO, Boerslid T, Oeveraasen M. Thermal and optical properties of living tissue: application to laserinduced hyperthermia. Lasers Surg Med 1985;5:589-602.

18 Yoshimura N, Kuriyama S, Ohuchi T, et al. Hyperthermia reduces the occurrence of proliferative vitreoretinopapthy reduces the occurrence of proliferative vitreoretinopapthy in a rabbit model. Invest Ophthalmol Vis Sci 1992;33:404-9. Macular Photocoagulation Study Group. Visual outcome after laser photocoagulation for subfoveal choroidal neovascularisation secondary to age-related macular degeneration: the influence of the initial lesion size and in tial visul acuity. Arch Ophthalmol 1994;112:480-8. 
20 Gelfand YA, Linn S, Miller B. The application of the macular photocoagulation study eligibility criteria for laser treatment in age-related macular degeneration. Ophthalmic Surg Lasers 1997;28:823-7.

21 Reichel E, Berrocal AM, Ip M, et al. Transpupillary themotherapy of occult subfoveal choroidal neovascularization in patients with age-related macular degeneration. Ophthalmology 1999;106:1908-14.

22 Bergink GJ, Hoying CB, Maazen vd RWM, et al. A randomized controlled clinical trial on the efficacy of radiation therapy in the control of subfoveal choroidal neovascularisation in age-related macular degeneration: radiation versus observation. Graefes Arch Clin Exp Ophthalmol 1998;236:321-5.

23 Holz FG, Engelhart-Cabillic R, Unnebrink K, et al. Prospective, randomized, double-blind trial on radiation therapy for neovascular age-related macular degeneration (RAD study). Ophthalmology 1999;106:2239-47.

24 Treatment of age-related macular degeneration with photodynamic therapy (TAP) Study Group. Photodynamic therapy of subfoveal choroidal neovascularization in age-related macular degeneration with verteporfin. Arch Ophthalmol 1999;117:1329-45.

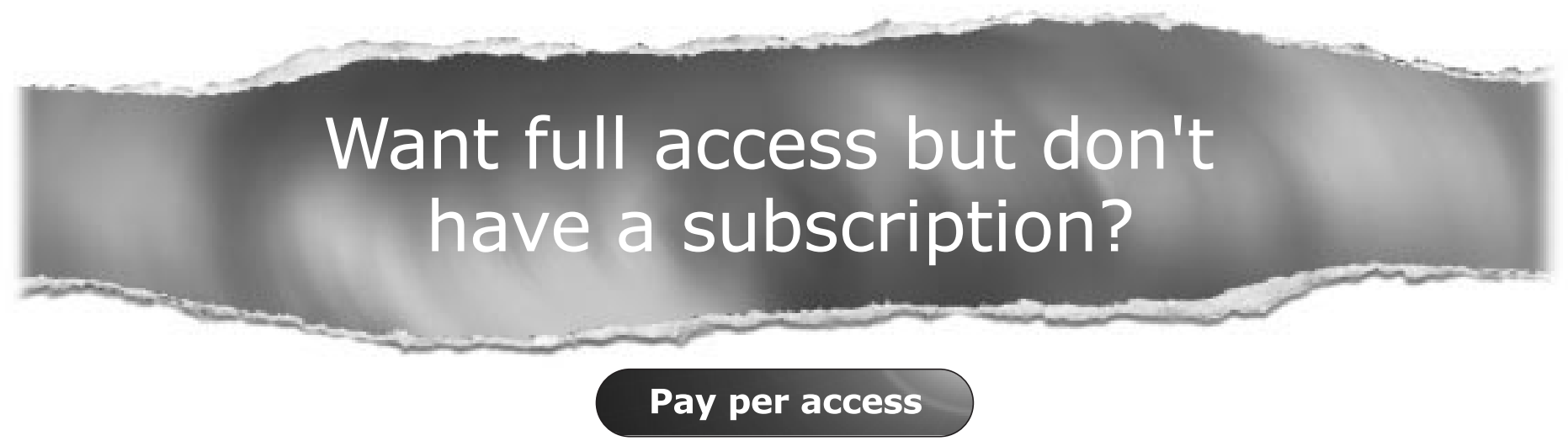

For just US $\$ 25$ you can have instant access to the whole website for 30 days. During this time you will be able to access the full text for all issues (including supplements) available. You will also be able to download and print any relevant pdf files for personal use, and take advantage of all the special features British Journal of Ophthalmology online has to offer.

\section{www.bjophthalmol.com}

